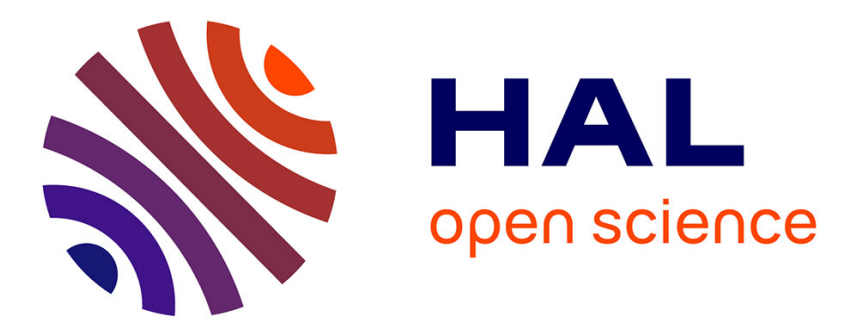

\title{
Spatial distribution of Pharmaceuticals within the particulate phases of a peri-urban stream
}

Lauriane Ledieu, Anaëlle Simonneau, Thomas Thiebault, L. Fougere, E. Destandau, O. Cerdan, Fatima Laggoun-Défarge

\section{- To cite this version:}

Lauriane Ledieu, Anaëlle Simonneau, Thomas Thiebault, L. Fougere, E. Destandau, et al.. Spatial distribution of Pharmaceuticals within the particulate phases of a peri-urban stream. Chemosphere, 2021, 279, pp.130385. 10.1016/j.chemosphere.2021.130385 . insu-03183855

\section{HAL Id: insu-03183855 \\ https://hal-insu.archives-ouvertes.fr/insu-03183855}

Submitted on 29 Mar 2021

HAL is a multi-disciplinary open access archive for the deposit and dissemination of scientific research documents, whether they are published or not. The documents may come from teaching and research institutions in France or abroad, or from public or private research centers.
L'archive ouverte pluridisciplinaire HAL, est destinée au dépôt et à la diffusion de documents scientifiques de niveau recherche, publiés ou non, émanant des établissements d'enseignement et de recherche français ou étrangers, des laboratoires publics ou privés. 


\section{Journal Pre-proof}

Spatial distribution of Pharmaceuticals within the particulate phases of a peri-urban stream

L. Ledieu, A. Simonneau, T. Thiebault, L. Fougere, E. Destandau, O. Cerdan, F. Laggoun

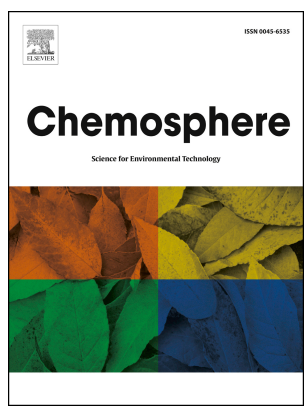

PII:

S0045-6535(21)00855-9

DOI:

https://doi.org/10.1016/j.chemosphere.2021.130385

Reference: CHEM 130385

To appear in: $\quad E C S N$

Received Date: 23 October 2020

Revised Date: 3 March 2021

Accepted Date: 22 March 2021

Please cite this article as: Ledieu, L., Simonneau, A., Thiebault, T., Fougere, L., Destandau, E., Cerdan, O., Laggoun, F., Spatial distribution of Pharmaceuticals within the particulate phases of a peri-urban stream, Chemosphere, https://doi.org/10.1016/j.chemosphere.2021.130385.

This is a PDF file of an article that has undergone enhancements after acceptance, such as the addition of a cover page and metadata, and formatting for readability, but it is not yet the definitive version of record. This version will undergo additional copyediting, typesetting and review before it is published in its final form, but we are providing this version to give early visibility of the article. Please note that, during the production process, errors may be discovered which could affect the content, and all legal disclaimers that apply to the journal pertain.

() 2021 Published by Elsevier Ltd. 
Lauriane Ledieu: Conceptualization, Investigation, Validation, Writing - Original Draft, Visualization. Anaëlle Simonneau: Conceptualization, Supervision, Writing - Review \& Editing, Project administration, Funding acquisition. Thomas Thiebault: Conceptualization, Methodology, Validation, Writing - Review \& Editing. Laëtitia Fougère: Methodology, Resources, Writing - Review \& Editing. Emilie Destandau: Methodology, Resources. Olivier Cerdan: Conceptualization, Supervision, Writing - Review \& Editing. Fatima Laggoun: Supervision, Project administration. 
SPATIAL DISTRIBUTION OF PHARMACEUTICALS WITHIN THE PARTICULATE PHASES OF A PERI-URBAN STREAM

\author{
L. Ledieu ${ }^{1}$, A. Simonneau ${ }^{1}$, T. Thiebault ${ }^{2}$, L. Fougere ${ }^{3}$, E. Destandau ${ }^{3}$, O. Cerdan ${ }^{4}$, F. Laggoun ${ }^{1}$
}

${ }^{1}$ Univ. Orléans, CNRS, BRGM, ISTO, UMR 7327, F-45071, Orléans, France (lauriane.ledieu@cnrs orleans.fr, anaelle.simonneau@univ-orleans.fr)

${ }^{2}$ EPHE, PSL University, UMR 7619 METIS (SU, CNRS, EPHE), 4 Place Jussieu, F-75005, Paris, France

${ }^{3}$ Univ Orleans, CNRS, ICOA, UMR 7311, 45067 Orleans, France

${ }^{4}$ BRGM, 3 avenue Claude Guillemin, 45060 Orléans, France

\title{
Abstract
}

Pharmaceutical products (PPs) are consumed worldwide and are continuously released into hydrological environments, but are not efficiently removed by sewage treatment plants. Their occurrence within the dissolved phase has been extensively studied, but only a few articles concern solid matrices. The mechanisms and extent of sorption depend on the properties of both the molecules (degradability, charge, hydrophobicity) and the matrices (clay content, organic matter content), making the spatio-temporal distribution of PPs in natural environments complex and poorly elucidated. To improve our understanding of PP distribution at a catchment scale, this study investigated different groups of molecules with varying solubility and charges, in water, suspended particulate matter, bed-load and pond sediments. The Egoutier stream, which collects the sewage effluents from two health institutions sewage effluents, is a good candidate for this investigation. Results indicate that PP occurrences in the different particulate compartments were mainly regulated by their wastewater occurrences and charges. Particulate phases all along the Egoutier stream were characterized by a limited clay content (i.e. less than $1 \%$ ) and significant organic carbon content (i.e. between $0.3 \%$ and $18.0 \%$ ) favouring non-specific adsorption. Therefore, neutral PPs, exhibiting higher discharge rates, persistence and hydrophobicities in comparison with cationic and anionic molecules, were the most abundant PPs in the particulate phases of this catchment. In bedload sediments, global PP spatial distributions reflected discharge sites and sedimentary accumulation zones, mostly that of organic matter. Spatial distributions of the more hydrophobic and persistent PP in the particulate phases thus followed the stream sedimentary dynamic. 


\section{Introduction}

Environmental and societal concerns about the occurrence of pharmaceutical products (PPs) within aquatic systems started in the 1970s (Hignite \& Azarnoff, 1977). These molecules are consumed worldwide (Jjemba, 2006; Gracia-Lor et al., 2010) and are continuously released into the environment (Loos et al., 2009) as chemical cocktails (Petrie et al., 2015; Kaushal et al., 2020). PPs can be bioaccumulated in aquatic organisms and transferred to the food chain (Sumpter et al., 1996), with negative effects on animal and human health (Gracia-Lor et al., 2010). Research efforts have therefore increased since the 1990s (Hughes et al., 2013) and PPs were qualified as an emerging class of contaminants (Boreen et al., 2003; Da Silva et al., 2011). The long-term ecotoxicological effects of these micropollutants remain unclear (Gracia-Lor et al., 2010) and thus represent a major environmental and societal issue. Understanding PP dynamics in hydrosystems is therefore needed in order to manage environmental contamination (Dobor et al., 2012; Petrie et al., 2015; Thiebault, 2020; Boulard et al., 2020).

In the European Union, about 3,000 PPs are approved for medical treatment (Da Silva et al., 2011), among which psychotropics (Calisto \& Esteves, 2009), anti-inflammatory agents, $\beta$-blockers (Petrie et al., 2015) and analgesics (Verlicchi et al., 2010) are the most frequently prescribed. France has a high drug consumption; for example, in 2018 average spending per inhabitant amounted to $488 €$ (Leem, 2020). High releases are therefore observed in freshwater aquatic environments (Fekadu et al., 2019), but only a few studies have been conducted on French rivers (Tamtam et al., 2008; Munoz, 2009; Hughes et al., 2013). These studies evidenced the presence of PPs in both small and large basins comprising urban areas (Feitosa-Felizzola \& Chiron, 2009; Mompelat et al., 2011).

Significant proportions of the consumed PPs can be excreted in an unchanged form (Baranowska \& Kowalski, 2010), and therefore transferred toward wastewater treatment plants (WWTP). The presence of PPs in hydrosystems is then the consequence of the incomplete removal of PPs in domestic and hospital sewage in WWTPs (Kümmerer, 2009). These micropollutants are subject to 
degradation, dilution and sorption processes but can be transported over long distances (Tamtam et al., 2008; Aminot et al., 2015). PPs are considered to be less persistent than other types of organic contaminants (such as polycyclic aromatic hydrocarbons and polychlorinated biphenyls), as they have fewer interactions with particulate phases because of their lower hydrophobicity (Svahn \& Björklund, 2015; Boulard et al., 2020) and are thus less likely to be transported through sediment transport (Loos et al., 2009). This pathway is consequently often neglected, but some PPs also display significant affinities with solid organic and mineral matrices (Löffler et al., 2005; Vazquez-Roig et al., 2010; Da Silva et al., 2011; Martínez-Hernández et al., 2014; Koba et al., 2018).

In recent decades, analytical procedures that assist in distinguishing and quantifying PPs in solid matrices have been developed especially through pressurized liquid extraction (PLE, Jelić et al., 2009) followed by ultra-high performance liquid chromatography in combination with tandem mass spectrometry (UHPLC-MS², Gracia-Lor et al., 2010). Studies evaluating PP distribution in sediments provide useful information as they may integrate larger time scales than the dissolved ones (Zhou \& Broodbank, 2014). Moreover, as the fate of PPs mainly depends on their partitioning between dissolved and particulate phases, an understanding of the sorption processes is required (MartínezHernández et al., 2014). Several studies conducted through batch experiments therefore evaluated the type of interactions involved in PP adsorption (Yamamoto et al., 2009), the difference in molecules' mobility (Scheytt et al., 2005), the role of solid matrix composition and the potential desorption of PPs (Stein et al., 2008). Predicting the behaviour of PPs is complex because of the variety of processes and parameters involved in their adsorption (Al-Khazrajy \& Boxall, 2016) but partitioning is mainly driven by both PP (structure, charge, hydrophobicity, persistence) and particle characteristics (composition, texture; Vazquez-Roig et al., 2012; Martínez-Hernández et al., 2014; Thiebault et al., 2016).

The spatio-temporal evolution of PPs certainly depends on sources, consumption and discharge rates (Petrie et al., 2015; Wilkinson et al., 2017). In particulate phases, this evolution is also driven by 
particle composition and texture as well as by the physico-chemical and hydrological conditions of the hydrosystem (Kim \& Carlson, 2007; De Castro-Català et al., 2016). Consequently, PPs may show high spatial variabilities between different aquatic environments. Wastewaters from medical institutions display higher emissions than domestic ones (Kümmerer, 2009; Verlicchi et al., 2010; Huber et al., 2016) and small hydrosystems are more sensitive to these contaminations because of a lower dilution of anthropogenic inputs (Da Silva et al., 2011). At a basin scale, different spatial evolutions have already been observed. Schultz et al. (2010) measured increasing concentrations downstream of the WWTP effluent whereas Aminot et al. (2015) measured the highest accumulation near sewage discharging sites, where sediments presented a high organic carbon content. The same observations were made by Da Silva et al. (2011) and Zhou and Broodbank (2014), but variabilities according to streamflow conditions were also recorded. At the Loire Bretagne basin scale, Amalric et al. (2011) correlated observed contents with urban pressure levels. Because of the complexity of these influencing factors, the spatio-temporal evolution of PPs in solid matrices is rarely investigated (Fairbairn et al., 2015), especially when it comes to integrating different compartments of the aquatic environment (Wilkinson et al., 2017).

In this context, the present study attempts to provide new insights into PP occurrences within particulate phases of a small peri-urban stream as these sites are often neglected while represent hotspots of contamination. Their occurrences were also used to study the spatio-temporal accumulation and/or transportation of this kind of contaminants at catchment scale, in both suspended particulate matter and sediments (bed-load and pond sediments). The catchment of the peri-urban Egoutier stream, a tributary of the Loire River, which collects the wastewaters from two medical institutions, was chosen as the study site. These point sources represent a good opportunity to improve our understanding of PPs spatio-temporal distribution as well as the impact of these effluents on stream quality. 
10 PPs were investigated, based on their consumption in the European Union (e.g. psychotropics, anti-inflammatory agents, $\beta$-blockers and analgesics; Calisto \& Esteves, 2009; Verlicchi et al., 2010; Petrie et al., 2015) as well as their detection frequency in aquatic environments (e.g. anticonvulsants and opioids; Clara et al., 2004; Campos-Mañas et al., 2018). The occurrence of these PPs was investigated in the particulate phases at the catchment scale and in the dissolved phase of WWTP effluents. Environmental physico-chemical conditions, composition and textures of solid matrices were also characterized. Lastly, based on the analysis of PPs emissions and properties (persistence, charge state and lipophilicity), different factors driving the accumulation and spatial distribution of the molecules were identified.

\section{Material and Methods}

The Egoutier catchment is located east of Orléans, in the Loire River basin (Fig. 1). Characterized by a temperate climate with an average annual rainfall of $650 \mathrm{~mm}$ (Soucémarianadin \& Verbèque, 2007), this small lowland catchment $\left(27 \mathrm{~km}^{2}\right)$ is drained by the Egoutier stream. The mean slope gradient is $0.5 \%$ and the geological substrate is composed of Sologne sands and clays, Orleanais sands and Beauce limestone from upstream to downstream (Berger \& Desprez, 1969).

To study the spatial evolution of PPs following a source-to-sink logic, the area investigated in this work was restricted to the upstream part of the catchment, covering $8 \mathrm{~km}^{2}$ and including the Beulie pond in its central part (Fig. 1). In this part, the catchment is composed by solely of hydromorphic soils with clay-rich subsoil layers (Soucémarianadin \& Verbèque, 2007). The Egoutier stream is thus supplied by stormwater runoff, but also by effluents from two WWTPs and two stormwater point sources from urban areas. The two WWTPs treat effluents from a central army pharmacy (CAP) and a psychiatric hospital (PH, Fig. 1), respectively. CAP effluents are continuously 
not continuous and not monitored. Urban storm waters come from runoff processes on both CAP surfaces and urban areas in the eastern part of the catchment. The latter are collected in a network and released into a tributary of the stream (BLS-13b, Fig. 1).

[Figure 1]

Figure 1: Description of the upstream part of the Egoutier catchment area studied here with land covers (Inglada et al., 2017). Locations of the two sewage water effluents from the central army pharmacy (CAP) and the psychiatric hospital (PH) and of the samples collected in the dissolved phase (W), in suspended particulate matter (SPM), bed-load (BLS) and Beulie pond sediments (EG).

In order to observe PP transportation by suspended particulate matter (SPM) at the catchment scale, SPM (grey dots, Fig. 1) were sampled at three locations. The first samples were taken downstream the CAP WWTP effluent (SPM-1, Fig. 1) to characterize the SPM geochemical fingerprint of this medical institution. The second samples were collected downstream the Beulie pond (SPM-2, Fig. 1) to integrate the PH fingerprint and quantify PP transportation despite the strong accumulation zone constituted by the pond. Finally, the third samples were taken at the outlet of the catchment (SPM-3, Fig. 1) to measure the total export of PPs. To collect enough material, SPM were collected by using GEACOS (GranulomEtric pAssive Capture of dissolved matter \& Sediment, Simonneau et al., 2020) placed in the watercourse during about two months. Four campaigns were realized: between November 2018 and January 2019; March and June 2019; June and August 2019; and August and October 2019 (Table S1).

In 2018 and 2019, 15 bed-load sediment samples (BLS, brown dots, Fig. 1) were collected all along the watercourse to assess the PPs' spatial distribution and the impact level of WWTP effluents. BLS were sampled at each storm- and sewage water discharge, and upstream to downstream depending on confluence and accumulation zones, during both winters and summers (April 2018 and 2019; August 2018 and 2019, Table S1), using $50 \mathrm{~mL}$ polypropylene Falcon tubes. Because of some dry areas during summer, some replicates were not always sampled in summer (Table S1). 

2018, along a north-south transect using an Ekman Grab (EG, green dots, Fig. 1). All solid samples were then split into two parts; one was stored wet at $5{ }^{\circ} \mathrm{C}$ and the other was dried at $50^{\circ} \mathrm{C}$ during 48 h. collected in April 2017 and the CAP effluent (W-CAP, Fig. 1) in August 2018 (Table S1), using $10 \mathrm{~L}$ polyethylene bottles that were stored at $5^{\circ} \mathrm{C}$ before analysis.

Stream $\mathrm{pH}$ conditions were measured during each BLS sampling campaign. This parameter was determined with a portable pH meter MultiLine Multi 3630 IDS.

Particle size distributions for SPM samples were already given by the GEACOS technology (Simonneau et al., 2020). They were quantified by drying each GEACOS sieve from $1 \mathrm{~mm}$ to 250, 60, $\mathrm{mm}$ ) were determined using a laser particle sizer Mastersizer 3000 (Malvern) at the GEHCO laboratory. Results obtained are the relative percentages of four grain-size classes: 0 - $2 \mu \mathrm{m}$ for clay grain sizes, 2 - $63 \mu \mathrm{m}$ for silt grain sizes, $63-250 \mu \mathrm{m}$ for fine sand grain sizes and $250-1800 \mu \mathrm{m}$ for medium to coarse sand grain sizes.

Total organic carbon (TOC) contents were estimated by Rock-Eval pyrolysis (Behar et al., 2001) using a Rock Eval 6 turbo at the ISTO laboratory. Standards provided by Vinci Technologies were used to check the reproducibility of the measures. The mean error and mean correction factor of TOC measurements were $0.14 \%$ and $1 \%$, respectively. 
laboratory with an INEL diffractometer adjusted with a Debye-Scherrer configuration. ICDD (International Centre for Diffraction Data) PDF (Powder Diffraction File) characteristic diagrams were used to identify the minerals (Fig. S1).

3. Pharmaceutical contents

3.1. Chemical reagents

Standards for acetaminophen (ACM), atenolol (ATE), carbamazepine (CBZ), codeine (COD), diazepam (DIA), diclofenac (DIC), oxazepam (OXA), salicylic acid (SCA), tramadol (TRA) and trimethoprim (TRI) were purchased from Sigma-Aldrich with a purity $>98 \%$. The solvents used for PP extraction and separation, methanol $(\mathrm{MeOH})$, acetonitrile $(\mathrm{AcN})$ and formic acid $(\mathrm{HCOOH})$, were purchased from Fisher-Scientific, assuming an analytical grade (purity up to $99.95 \%)$.

\subsection{Extraction procedure}

Extraction procedures were carried out at the ISTO laboratory. For water samples solid phase extraction (SPE) using a Chromabond HR-X cartridge $(6 \mathrm{~mL} \times 500 \mathrm{mg}$, Macherey-Nagel) was performed. The cartridge was conditioned with $5 \mathrm{~mL}$ of $\mathrm{MeOH}$ and $5 \mathrm{~mL}$ of ultra-pure water $\left(\mathrm{H}_{2} \mathrm{O}\right)$. The cartridge was then filled with $250 \mathrm{~mL}$ of sample before being washed with $5 \mathrm{~mL}$ of $\mathrm{H}_{2} \mathrm{O}$ and dried for 30 minutes. The analytes were finally eluted with $3 \times 5 \mathrm{~mL}$ of $\mathrm{MeOH}$. Complementarily, between 1 and $7 \mathrm{~g}$ of bulk sediments, depending on their composition, were extracted by pressurized liquid extraction (PLE) using an ASE-200 (Dionex, $100{ }^{\circ} \mathrm{C}$ and 1000 psi) and a mixture of $\mathrm{MeOH} / \mathrm{H}_{2} \mathrm{O}(1: 1$, $\mathrm{v} / \mathrm{v}$ ). For both methods, eluates were then dried under nitrogen flow and reconstituted in $3 \mathrm{~mL}$ of $\mathrm{H}_{2} \mathrm{O}$. Solutions were filtered with a glass-fiber filter (GF/F, Whatman) prior to being stored at $5{ }^{\circ} \mathrm{C}$ before analysis. The recovery ratios of the investigated PPs (Table 1) during SPE and ASE were taken as those presented in Thiebault et al. (2017a, b), using the same protocol (Table S2). 
Table 1 : For each therapeutic molecule, abbreviation (Abb.), CAS-Number, formula, molecular weight (MW), charge state at $p H=7$ (Charge), pKa, solubility and logD are specified. ${ }^{a}$ : https://pubchem.ncbi.nlm.nih.gov; ${ }^{b}:$ www.drugbank.ca, ${ }^{c}$ : www.chemspider.com.

[Table 1]

\subsection{Quantification procedure}

Chromatographic separation was performed using an Ultimate 3000 RSLC (Rapid Separation Liquid Chromatography, Thermo Fisher Scientific) equipped with a Nucleodur $\mathrm{C}_{18}$ Gravity Column (150 mm x $2 \mathrm{~mm} ; 3 \mu \mathrm{m}$, Macherey-Nagel) at the ICOA laboratory. Separation was carried out at $30^{\circ} \mathrm{C}$ with two mobile phases: $\mathrm{H}_{2} \mathrm{O}$ (solvent $\mathrm{A}$ ) and $\mathrm{AcN}$ (solvent B), both acidified with $0.1 \%$ of $\mathrm{HCOOH}$. The total analysis time was 29 min with the elution gradient as follows: $95 \%$ to $5 \%$ of solvent A during 16 min, then $100 \%$ of $B$ during 3 min, followed by a return to initial conditions ( $95 \%$ of $A$ ) during $10 \mathrm{~min}$. The mass spectrometer was a TSQ Endura triple quadrupole equipment fitted with a heated electrospray ionization (H-ESI) interface (Thermo Fisher Scientific). The analytical performances of this method were developed in Thiebault et al. (2017a). For this work, only results with a signal-to-noise ratio higher than the limit of quantification (S/N > 10, Gracia-Lor et al., 2010; LOQ, Table S2) were used for interpretation. The sample analysis was systematically validated by a quality procedure comprising a calibration curve ( 6 standards), triplicates of 4 samples followed by one standard control and one blank (pure water), and a final calibration curve. For each PP, the identification parameters and quantification accuracy are detailed in Table S2. To ensure reproducibility of the quantification, mean variation coefficients were calculated by analysing triplicates of the standard solutions (Table S2).

\section{Results and discussion}

1. PPs occurrence and accumulation in the particulate phases

Among the 10 PPs investigated in the dissolved phase, 5 were quantified in W-CAP, whereas all the 10 were quantified in $\mathrm{W}-\mathrm{PH}$. The PP diversity found in $\mathrm{W}-\mathrm{PH}$ was therefore greater than in $\mathrm{W}-\mathrm{CAP}$, as were the PP concentrations (Fig. S2). In the W-CAP sample, SCA was the most abundant PP, 
exhibiting a concentration of $2170 \mathrm{ng} \cdot \mathrm{L}^{-1}$. TRI and CBZ exhibited medium contents with 290 and 120 ng. $\mathrm{L}^{-1}$, respectively, and OXA and DIC were the least abundant with concentrations reaching $20 \mathrm{ng} \cdot \mathrm{L}^{-1}$ (Fig. S2). In the W-PH sample, TRA and ACM exhibited the highest concentrations, with 7.97 and 6.33 $\mu \mathrm{g} . \mathrm{L}^{-1}$, respectively (Fig. S2) and DIC, DIA and TRI were the least concentrated PPs, with 70, 80 and 10 ng. L $^{-1}$, respectively (Fig. S2).

The 10 PPs were also quantified at least once in the particulate phases. Quantified in two solid samples, TRA was the least frequently detected but also the most concentrated PP, ranging from 41.9 to 5811.9 ng.g ${ }^{-1}$ (Fig. 2 and Table S4). Nevertheless, this high concentration appears surprising and should be considered with caution in view of the mean variations in its standard solutions (Table S2). ATE and COD exhibited low occurrences and concentrations in solid matrices, ranging from the limit of detection to 6.6 and $20.3 \mathrm{ng} \cdot \mathrm{g}^{-1}$, respectively (Fig. 2 and Table S4). DIC and ACM were more frequently detected but their concentrations did not exceed 6.7 and 16.9 ng.g ${ }^{-1}$, respectively (Fig. 2 and Table S4). With high abundance and medium to high contents, TRI, DIA and OXA ranged from the limit of detection to $27.5,39.6$ and $141.4 \mathrm{ng} . \mathrm{g}^{-1}$, respectively (Fig. 2 and Table S4). CBZ and SCA were detected ubiquitously in the particulate phases, ranging from the limit of detection to 130.5 and $176.2 \mathrm{ng} . \mathrm{g}^{-1}$, respectively (Fig. 2 and Table S4).

The different PPs presented various occurrences and accumulation rates depending on their sensitivity to degradation processes, their solubility and their discharge rates. Consistently with its high degradability (Table 2) and solubility (Table 1), ACM exhibited low concentrations and was seldom detected (Fig. 2 and Table S4). Conversely, the low solubility of DIC and DIA (Table 1) allows their frequent detection in solid matrices (Table S4) in spite of their low concentrations measured in the dissolved phase (Fig. S2). The high detection frequencies and contents of OXA, TRI and CBZ in solid matrices were consistent with their moderate to high emissions (Fig. S2) and persistence (Table 2). Moreover, OXA is the main metabolite of DIA (Baker et al., 2014). The ubiquity of SCA may be explained by its presence in all anthropogenic effluents at high levels, a behaviour already observed 
257

258

259

260

261

262

263

264

265

266

267

268

269

270

271

272

273

274

275

276

277

in other hydrosystems (Togola et al., 2008; Huber et al., 2016). Nevertheless, despite their moderate to high concentrations in the sewage effluents (Fig. S2) and persistence (Table 2), ATE, COD and TRA were the least frequently detected PPs (Fig. 2 and Table S4), suggesting that other parameters regulate their adsorption.

Table 2: Solid-water partition coefficient (Kd), persistence and major degradation processes (BT: biotransformation; PY: photolysis) of the investigated analgesics, antibiotics, anti-inflammatory agents, 6-blockers, opioids and psychotropics.

[Table 2]

As PPs are organic molecules, sorption can occur through different types of chemical interactions with both organic and mineral surfaces, depending on the molecular charges (MartínezHernández et al., 2014; Svahn \& Bjorklund, 2015). This speciation therefore plays a key role in PP adsorption and depends on the molecular structure and functional groups, varying with the $\mathrm{pH}$ value (Kümmerer, 2009). With pH values ranging from 6.9 to 9.5 (mean value of 7.5 ) in the Egoutier stream, ATE, COD and TRA were cationic, ACM, CBZ, DIA and OXA were neutral, and SCA and DIC were anionic (Table 1). Only the charge state of TRI may be influenced by such a range of pH values (Table 1 ), but it was generally mostly found as a neutral molecule (i.e. pKa $=7.2$ ). The mineralogical parts of the Egoutier stream solid matrices were composed of quartz, calcite, albite, orthoclase and smectite (Table S3, Fig. S1), consistently with the geology of the catchment (Berger and Desprez, 1969). Some exceptions such as the presence of aragonite in BLS collected at the CAP sewage effluent (BLS-2, Fig. S1) and the absence of smectite in BLS collected downstream the pond (BLS-13) were also observed (Table S3). All solid samples had sandy-loam textures and TOC levels ranging from 0.2 to $18.0 \%$ (Table S3). As clay minerals and organic matter are negatively charged, several studies have reported a good affinity of cationic PPs with particles (Ramil et al., 2010; MartínezHernández et al., 2014; Svahn \& Björklund, 2015; Boulard et al., 2020). In the present study, cationic, neutral and anionic PPs exhibited a detection frequency of 10, 65 and 66\%, respectively (Table S4). Their concentrations ranged from 3.8 to $20.3 \mathrm{ng} \cdot \mathrm{g}^{-1}$ (mean value of $9.9 \mathrm{ng} \cdot \mathrm{g}^{-1}$ ), 1.2 to $141.4 \mathrm{ng} \cdot \mathrm{g}^{-1}$ 
283

284

285

286

287

288

289

290

291

292

293

294

295

296

297

298

299

300

301

302

303

304

305

306

307

(mean value of $19.6 \mathrm{ng} \cdot \mathrm{g}^{-1}$ ) and 4.4 to $176.2 \mathrm{ng} \cdot \mathrm{g}^{-1}$ (mean value of $33.0 \mathrm{ng} \cdot \mathrm{g}^{-1}$ ), respectively (Fig. 2 and Table S4). The lower occurrences of cationic PPs in this study in comparison with others might be explained by higher TOC levels (e.g. 33\% in Svahn \& Björklund (2015)) or by different solid matrix grain-sizes, resulting in variations in the particles' cation exchange capacity (CEC), not characterized in Svahn and Björklund (2015) and Boulard et al. (2020). Consequently, the limited clay contents in Egoutier solid matrices (Table S3) may explain this result. Moreover, as hydrophobic interactions are known to contribute significantly to PP sorption, PP lipophilicity $(\log D$, Table 1$)$ therefore represents another characteristic that plays a key role in their accumulation in particulate phases (Yamamoto et al., 2009). The moderate hydrophobicity (Table 1) of the cationic PPs investigated may also contribute to their lower adsorption.

2. Distribution of PPs between the different compartments of the aquatic environment

Cocktails observed in the particulate phases collected at sewage discharging sites and downstream were consistent with those quantified in WWTP effluents. All the PPs quantified in the CAP effluent (CBZ, OXA, TRI, DIC and SCA, Fig. S2) were detected at least once in the BLS and SPM sampled downstream (Fig. 2 and Table S4). In the PH effluent, all the PPs investigated were quantified (Fig. S2) and were also detected in SPM and BLS sampled downstream its discharge (Fig. 2 and Table S4). Therefore, the particulate phases well reflect the sets of PPs released in the dissolved phase. Surprisingly, CBZ, TRI and SCA were also detected in the first BLS sample collected in the upstream part of the watercourse (BLS-1, Fig. 2 and Table S4), suggesting another source at the locality present in the upstream part of the catchment (Fig. 1). All the neutral and anionic PPs were also detected in the BLS samples collected at stormwater discharge sites (BLS-2 and BLS-13b, Fig. 2 and Table S4). This observation implies leaks in the sewage networks. Except for ACM, only detected in the CAP stormwater effluent, the cocktails of PPs observed in the BLS collected at these discharges were similar (Fig. 2 and Table S4). 
Figure 2: Detection and concentrations of atenolol (ATE), codeine (COD), tramadol (TRA), acetaminophen (ACM), carbamazepine (CBZ), diazepam (DIA), oxazepam (OXA), trimethoprim (TRI), diclofenac (DIC) and salicylic acid (SCA) in bedload sediment samples (BLS 1 to 14, Fig. 1) along the watercourse during the different campaigns. Pharmaceutical mean contents in suspended particulate matter samples (SPM 1 to 3, Fig. 1) and Eckman grabs (EG 1 to 3, Fig. 1) according to sampling period. Dotted lines represent stormwater and sewage water effluents, as well as the Beulie pond location.

Despite the consistency between the dissolved and particulate phases, the different solid matrices demonstrated various rates of PP accumulation. SPM contents in PPs were less diversified and less concentrated than in BLS samples (Fig. 2 and Table S4). Indeed, the least frequently detected PPs, ACM, ATE, COD, TRA and DIC, were not quantified in SPM and each quantified PP presented a lower concentration in SPM than in BLS samples (Fig. 2 and Table S4). SCA was the most abundant and the most concentrated in both compartments but did not exceed $32.5 \mathrm{ng} \cdot \mathrm{g}^{-1}$ in SPM, whereas it reached 169.4 ng..$^{-1}$ in BLS samples (Fig. 2 and Table S4). TRI was also frequently quantified in SPM, ranging from 1.2 to $12.1 \mathrm{ng} . \mathrm{g}^{-1}$ while reaching $27.5 \mathrm{ng} \cdot \mathrm{g}^{-1}$ in BLS samples (Fig. 2 and Table S4). OXA, DIA and CBZ were quantified only once in SPM, in concentrations of 24.3, 24.8 and $28.0 \mathrm{ng} \cdot \mathrm{g}^{-1}$, respectively, in contrast with BLS samples where they reached 141.4, 39.6 and 130.5 ng. $\mathrm{g}^{-1}$, respectively (Fig. 2 and Table S4). Total PP concentrations therefore did not exceed $64 \mathrm{ng} . \mathrm{g}^{-1}$ in SPM, but reached $212 \mathrm{ng} \cdot \mathrm{g}^{-1}$ in BLS (without considering the exceptional levels of TRA in one sample, Table S4). This tendency is not in agreement with other studies, in which higher contents were measured in SPM than in BLS in both large and small hydrosystems (Da Silva et al., 2011; Aminot et al., 2015; Comtois-Marotte et al., 2017). These studies designated SPM as a better sorbent because of its higher levels of TOC and fine particles. However in our case, the sandy-clay soils of the Egoutier 332 catchment (Soucémarianadin \& Verbèque, 2007) lead to a coarse texture of SPM (Table S3). SPM contents in TOC (ranging from 4.2 to $6.6 \%$, Table S3) and fine particles $(2-63 \mu \mathrm{m}$, ranging from 0.7 to 7.9\%, Table S3) were therefore far lower than those of the BLS samples collected in strong 
composition explains the limited occurrence of less hydrophobic (Table 1 ) and persistent PPs (ACM, ATE, COD, TRA and DIC, Table 2) which were released in lower quantities (Fig. 2 and Table S4). Moreover, sorption regulates PP sedimentation or transportation at the catchment scale (Lahti \& Oikari, 2011). This therefore suggests that lower interactions with SPM limit the transportation of ACM, ATE, COD, TRA and DIC over long distances.

As the Beulie pond sediments are mainly supplied by SPM decantation, these two compartments consequently exhibited similar fingerprints (Fig. 2 and Table S4). Despite the strong accumulation of organic matter (reaching $14.3 \%$ ) and fine particles $(2-63 \mu \mathrm{m}$, reaching $72.1 \%$, Table S3), only the PPs transported by SPM were also observed in the pond sediments (Fig. 2 and Table S4). ACM, ATE, COD, TRA and DIC were absent, suggesting lower transportation distances (Fig. 2 and Table S4) and retention zones within the catchment area. Moreover, lower concentrations in the EG samples than in BLS ones highlight particle accumulation in specific locations upstream of the pond (Fig. 2 and Table S4).

\section{Spatial evolution of PPs in the particulate phases at the catchment scale}

PP contents were highly variable in space and time. In order to have a high-resolution visualization of PPs' spatial evolution in particulate phases, the most persistent (Table 2) neutral and cationic PPs are represented in Figure 3. CBZ, DIA, OXA, ATE and COD were selected because of their concentrations in specific locations compared to ubiquitous PPs such as TRI and SCA. Moreover, they have known specific sources (Fig. S2) and exhibited good affinities with sediments. Total concentrations of these neutral and cationic PPs were therefore compared to TOC and fine particle levels (Fig. 3), as these fractions are the best sorbents (Aminot et al., 2015).

Thanks to their properties (hydrophobicity and persistence, Table 1 and 2), some of these PPs have already been used as tracers to qualify anthropogenic impacts on the environment (Warner et al., 2019). This is mainly the case for CBZ (Clara et al., 2004; Maskaoui \& Zhou, 2010) and sometimes 
361

362

363

364

365

366

367

368

369

370

371

372

373

374

375

376

377

378

379

380

381

382

383

384

385

386

387

OXA (Amalric et al., 2011). These more persistent PPs generally present lower spatio-temporal variabilities (Vystavna et al., 2013; Klaminder et al., 2015) but this trend was not observed in the present study (Fig. 3), as the particulate phase contents of every PP were highly variable in space and time (Fig. 2 and 3).

[Figure 3]

Figure 3: Spatial evolution of persistent neutral (carbamazepine (CBZ), diazepam (DIA) and oxazepam (OXA)) and cationic molecules (atenolol (ATE) and codeine (COD)) total concentrations $(\Sigma)$ compared to the spatial evolution of total organic carbon (TOC) and fine particles $(0-63 \mu \mathrm{m})$ percentages in suspended particulate matter (SPM 1 to 3, Fig. 1), bed-load (BLS 1 to 14, Fig. 1) and Beulie pond sediments (mean contents of EG 1 to 3, Fig. 1).

As already observed in other studies (Da Silva et al., 2011; Zhou \& Broodbank, 2014; Aminot et al., 2015), high concentrations are observed at stormwater and WWTP effluent discharge sites (BLS-2, BLS-3 and BLS-7, Fig. 3). Nevertheless, specific accumulation zones also appeared downstream the PP sources (Fig. 3). In the upstream part of the catchment, between the CAP and PH effluents, PPs were always present but sparsely accumulated (Fig. 3), consistently with the low discharges measured in the CAP sewage waters (Fig. S2). This implies PP transportation, as observed in SPM samples, but only a small deposition of sediments in this part of the watercourse (Fig. 3). Indeed, low sediment thicknesses not exceeding 3 centimetres were measured during the sampling campaigns. Given the higher discharges of the PH effluent (Fig. S2), a stronger accumulation of PPs was unsurprisingly observed at its discharge (Fig. 3). Large accumulation zones also appeared between this effluent and the Beulie pond (Fig. 3) suggesting specific deposition zones in this part of the watercourse. Indeed, the specific PPs released by the PH (ATE and COD) as well as the most abundant PPs (CBZ, DIA and OXA) exhibited local concentrations downstream the PH (BLS-9 and BLS11, Fig. 2 and 3) where sediment layers up to 67 centimetres thick were measured. These zones stored high proportions of fine particles (more than $46 \%$ of silt, Table S3) but PP amounts mainly followed the large variations in organic matter levels (Fig. 3). This was also observed in the Beulie 
388

389

390

391

392

393

394

395

396

397

398

399

400

401

402

403

404

405

406

407

408

409

410

411

pond where PP distribution corresponds to that of the TOC (Fig. 3). The main PP-bearing phase also appeared to be organic matter. Besides, sorption processes for PPs such as CBZ were already demonstrated to be dominated by organic carbon-partitioning (Fairbairn et al., 2015).

Surprisingly, higher concentrations were generally observed in spring (Fig. 2 and 3). This can be linked to a lower efficiency of degradation processes, which may be limited by a minimal residence time at higher flow rates (Amalric et al., 2011) and in colder weather (Kim \& Carlson, 2007). However, an opposite trend was already observed as higher stormwater supplies in spring can dilute anthropogenic inputs (Kolpin et al., 2004) and adsorption can be enhanced by longer incubation times during low flow periods (Fairbairn et al., 2015). In our case, this tendency seems to be mainly driven by higher supplies in organic matter and fine particles (Fig. 3). It also illustrates seasonal variations of the sedimentary dynamic, as contaminated particles are transported and deposited at greater distances from PP sources in spring (Fig. 2 and 3).

In BLS collected downstream of the pond, PP concentrations were under the LOQ (Fig. 3; Table S4). Given the absence of WWTP effluents in the downstream part of the catchment, this evidences the storage capacity of the pond, which is also demonstrated by the decreasing TRI and SCA concentrations towards the outlet in SPM samples (Fig. 2, 3 and Table S4). Nevertheless, CBZ, OXA and COD presented higher concentrations in SPM collected downstream the pond than at the other sampling locations (Fig. 2, 3 and Table S4), illustrating the transport of some contaminated particles beyond the pond. This implies that particles are preferentially transported rather than deposited in this part of the watercourse. Indeed, except for those collected at the stormwater effluent (BLS-13b), BLS also demonstrated lower fine grain-size particles $(2-63 \mu \mathrm{m})$ and TOC levels (Table S3 and Fig. 3). The catchment therefore has two distinct sedimentary dynamics with low transportation and strong accumulation zones in the upstream part, in contrast to high transportation and low deposition in the downstream part. At the outlet, SPM therefore represents 
412

413

414

415

the highest risk by spreading PPs over long distances but thanks to the pond and the absence of new sewage water releases, contamination levels remained low.

\section{Conclusions}

All the PP investigated were quantified in the particulate phases, but in various abundances and levels. PP discharges and persistence drive their occurrences and the observed concentrations depend on the properties of both the released molecules (charge, persistenice and lipophilicity) and the receiving environment (physico-chemical conditions, composition, and texture), as it drives the processes involved in adsorption. In the Egoutier stream, the low contents in clay grain-sizes, the relatively high persistence and discharges of neutral PPs led to the predominance of hydrophobic interactions with organic matter.

Particulate phases, mostly bed-load sediments, well represent the PP cocktails released into the aquatic environment. The different particulate compartments accumulate PPs in different ways. Depending on the composition of the suspended particulate matter, the prevalence of neutral PPs and their sorption to organic matter in the Egoutier stream, these solid matrices exhibit low interaction with cationic molecules. The latter are consequently transported over smaller distances and not stored in the pond sediments. In the same way, the most degradable PPs are sparsely accumulated in bed-load sediments, but not in suspended solids and pond sediments.

In accordance with these conclusions, the spatial distribution of PPs in particulate phases at the Egoutier scale mainly reflects the discharge sites. In addition, the most abundantly adsorbed and persistent molecules highlight the sedimentary dynamic of the watercourse, in particular that of organic matter. Sedimentary deposition areas thus strongly stored the molecules because of large deposits of organic matter. These accumulation zones are mainly located upstream of the pond, evidencing the strong storage capacity of the Beulie pond and a preferential transportation over deposition in the downstream part of the catchment. Seasonal variations also appear to be driven by 
limited degradation processes and/or higher supplies in organic matter. Moreover, PPs can be transported over longer distances in periods of high flows.

To go further, with such an anthropogenic gradient and point sources of sewage and storm waters, the Egoutier stream could be a favourable place to investigate the spatial distribution of other types of contaminants in the different particulate compartments. Moreover, the sediments of the Beulie pond, which has been in place for centuries, could represent an archive of past contamination levels.

\section{Acknowledgments}

This work and the PhD grant of L. Ledieu were funded by the Région Centre Val de Loire (France) and are part of the Academic Initiative Project MOSAIC led by A. Simonneau. This work was also supported by a grant overseen by the French National Research Agency (ANR) as part of the "Investments d'Avenir" Programme LabEx VOLTAIRE, 10-LABX-0100. This study benefited from collaboration with the GéHCO laboratory and J-P. Bakyonoo is warmly thanked for his help during analysis. We are grateful to P. Penhoud and R. Boscardin for analytical and technical support in XRD analysis and Rock Eval pyrolysis, respectively. L. Baude, H. Alphonse and S. Picault are thanked for the sampling authorization at the G. Daumézon hospital and in the town of Semoy. We acknowledge M. Hatton and L. Le Forestier during SPM and BLS sampling as well as A. Foucher for support during the Beulie pond interface sediments survey.

\section{References}

Agunbiade, F. O., \& Moodley, B. (2016). Occurrence and distribution pattern of acidic pharmaceuticals in surface water, wastewater, and sediment of the Msunduzi River, Kwazulu-Natal, South Africa. Environmental Toxicology and Chemistry, 35(1), 36-46.

Al-Khazrajy, O. S., \& Boxall, A. B. (2016). Impacts of compound properties and sediment characteristics on the sorption behaviour of pharmaceuticals in aquatic systems. Journal of hazardous materials, 317, 198-209. 
Amalric, L., Togola, A., \& Lopez, B. (2011). Suivi des résidus de substances pharmaceutiques dans les systèmes aquatiques du bassin Loire-Bretagne. Rapport final. BRGM/RP-59371-FR.

Aminot, Y., Litrico, X., Chambolle, M., Arnaud, C., Pardon, P., \& Budzindki, H. (2015). Development and application of a multi-residue method for the determination of 53 pharmaceuticals in water, sediment, and suspended solids using liquid chromatography-tandem mass spectrometry. Analytical and bioanalytical chemistry, 407(28), 8585-8604.

Ashton, D., Hilton, M., \& Thomas, K. V. (2004). Investigating the environmental transport of human pharmaceuticals to streams in the United Kingdom. Science of the total environment, 333(1-3), 167184.

Baena-Nogueras, R. M., González-Mazo, E., \& Lara-Martín, P. A. (2017). Degradation kinetics of pharmaceuticals and personal care products in surface waters: photolysis vs biodegradation. Science of the total environment, 590, 643-654.

Baker, D. R., Barron, L., \& Kasprzyk-Hordern, B. (2014). Illicit and pharmaceutical drug consumption estimated via wastewater analysis. Part A: chemical analysis and drug use estimates. Science of the total environment, 487, 629-641.

Baranowska, I., \& Kowalski, B. (2010). The development of SPE procedures and an UHPLC method for the simultaneous determination of ten drugs in water samples. Water, Air, \& Soil Pollution, 211(1-4), 417-425.

Behar, F., Beaumont, V., \& Penteado, H. D. B. (2001). Rock-Eval 6 technology: performances and developments. Oil \& Gas Science and Technology, 56(2), 111-134.

Bendz, D., Paxéus, N. A., Ginn, T. R., \& Loge, F. J. (2005). Occurrence and fate of pharmaceutically active compounds in the environment, a case study: Höje River in Sweden. Journal of hazardous materials, 122(3), 195-204.

Berger, G., Desprez, N. (1969). Carte de France (1/50 000), “Orléans (363)". BRGM, Orléans.

Boreen, A. L., Arnold, W. A., \& McNeill, K. (2003). Photodegradation of pharmaceuticals in the aquatic environment: a review. Aquatic Sciences, 65(4), 320-341.

Boulard, L., Dierkes, G., Schlüsener, M. P., Wick, A., Koschorreck, J., \& Ternes, T. A. (2020). Spatial distribution and temporal trends of pharmaceuticals sorbed to suspended particulate matter of German rivers. Water Research, 171, 115366.

Calisto, V., \& Esteves, V. I. (2009). Psychiatric pharmaceuticals in the environment. Chemosphere, 77(10), 1257-1274.

Campos-Mañas, M. C., Ferrer, I., Thurman, E. M., \& Agüera, A. (2018). Opioid occurrence in environmental water samples-a review. Trends in Environmental Analytical Chemistry, 20, e00059.

Clara, M., Strenn, B., \& Kreuzinger, N. (2004). Carbamazepine as a possible anthropogenic marker in the aquatic environment: investigations on the behaviour of carbamazepine in wastewater treatment and during groundwater infiltration. Water research, 38(4), 947-954.

Comtois-Marotte, S., Chappuis, T., Duy, S. V., Gilbert, N., Lajeunesse, A., Taktek, S., Desrosiers, M., Veilleux, E., \& Sauvé, S. (2017). Analysis of emerging contaminants in water and solid samples using high resolution mass spectrometry with a $Q$ Exactive orbital ion trap and estrogenic activity with YESassay. Chemosphere, 166, 400-411.

Da Silva, B. F., Jelić, A., López-Serna, R., Mozeto, A. A., Petrovic, M., \& Barceló, D. (2011). Occurrence and distribution of pharmaceuticals in surface water, suspended solids and sediments of the Ebro river basin, Spain. Chemosphere, 85(8), 1331-1339. 
De Castro-Català, N., Kuzmanovic, M., Roig, N., Sierra, J., Ginebreda, A., Barceló, D., Pérez, S., Petrovic, M., Picó, Y., Schuhmacher, M., \& Muñoz, I. (2016). Ecotoxicity of sediments in rivers: Invertebrate community, toxicity bioassays and the toxic unit approach as complementary assessment tools. Science of the total environment, 540, 297-306.

Dobor, J., Varga, M., \& Záray, G. (2012). Biofilm controlled sorption of selected acidic drugs on river sediments characterized by different organic carbon content. Chemosphere, 87(2), 105-110.

Fairbairn, D. J., Karpuzcu, M. E., Arnold, W. A., Barber, B. L., Kaufenberg, E. F., Koskinen, W. C., Novak, P. J., Rice, P. J., \& Swackhamer, D. L. (2015). Sediment-water distribution of contaminants of emerging concern in a mixed use watershed. Science of the total environment, 505, 896-904.

Feitosa-Felizzola, J., \& Chiron, S. (2009). Occurrence and distribution of selected antibiotics in a small Mediterranean stream (Arc River, Southern France). Journal of Hydrology, 364(1-2), 50-57.

Fekadu, S., Alemayehu, E., Dewil, R., \& Van der Bruggen, B. (2019). Pharmaceuticals in freshwater aquatic environments: A comparison of the African and European challenge. Science of the Total Environment, 654, 324-337.

Gracia-Lor, E., Sancho, J. V., \& Hernández, F. (2010). Simultaneous determination of acidic, neutral and basic pharmaceuticals in urban wastewater by ultra high-pressure liquid chromatographytandem mass spectrometry. Journal of Chromatography A, 1217(5), 622-632.

Hignite, C., \& Azarnoff, D. L. (1977). Drugs and drug metabolites as environmental contaminants: chlorophenoxyisobutyrate and salicylic acid in sewage water effluent. Life Sciences, 20(2), 337-341.

Huber, S., Remberger, M., Kaj, L., Schlabach, M., Jörundsdóttir, H. Ó., Vester, J., Arnórsson, M., Mortensen, I., Swartson R., \& Dam, M. (2016). A first screening and risk assessment of pharmaceuticals and additives in personal care products in waste water, sludge, recipient water and sediment from Faroe Islands, Iceland and Greenland. Science of The Total Environment, 562, 13-25.

Hughes, S. R., Kay, P., \& Brown, L. E. (2013). Global synthesis and critical evaluation of pharmaceutical data sets collected from river systems. Environmental science \& technology, 47(2), 661-677.

Inglada, J., Vincent, A., Thierion, V. (2017). Theia OSO Land Cover Map 2106 [Data set]. Zenodo.

Jelić, A., Petrović, M., \& Barceló, D. (2009). Multi-residue method for trace level determination of pharmaceuticals in solid samples using pressurized liquid extraction followed by liquid chromatography/quadrupole-linear ion trap mass spectrometry. Talanta, 80(1), 363-371.

Jjemba, P. K. (2006). Excretion and ecotoxicity of pharmaceutical and personal care products in the environment. Ecotoxicology and environmental safety, 63(1), 113-130.

Kaushal, S. S., Wood, K. L., Galella, J. G., Gion, A. M., Haq, S., Goodling, P. J., Haviland, K. A., Reimer, J. E., Morel, C. J., Wessel, B., Nguyen, W., Hollingsworth, J. W., Mei, K., Leal, J., Widmer, J., Sharif, R., Mayer, P. M., Newcomer Johnson, T. A., Delaney Newcomb, K., Smith, E. \& Belt, K. T. (2020). Making 'chemical cocktails'-Evolution of urban geochemical processes across the Periodic Table of elements. Applied Geochemistry, 119, 104632.

Kim, S. C., \& Carlson, K. (2007). Temporal and spatial trends in the occurrence of human and veterinary antibiotics in aqueous and river sediment matrices. Environmental science \& technology, 41(1), 50-57.

Klaminder, J., Brodin, T., Sundelin, A., Anderson, N. J., Fahlman, J., Jonsson, M., \& Fick, J. (2015). Long-term persistence of an anxiolytic drug (oxazepam) in a large freshwater lake. Environmental science \& technology, 49(17), 10406-10412. 
Koba, O., Grabicova, K., Cerveny, D., Turek, J., Kolarova, J., Randak, T., Zlabek, V., \& Grabic, R. (2018). Transport of pharmaceuticals and their metabolites between water and sediments as a further potential exposure for aquatic organisms. Journal of hazardous materials, 342, 401-407.

Kolpin, D. W., Skopec, M., Meyer, M. T., Furlong, E. T., \& Zaugg, S. D. (2004). Urban contribution of pharmaceuticals and other organic wastewater contaminants to streams during differing flow conditions. Science of the Total Environment, 328(1-3), 119-130.

Koumaki, E., Mamais, D., Noutsopoulos, C., Nika, M. C., Bletsou, A. A., Thomaidis, N. S., Eftaxias, A., \& Stratogianni, G. (2015). Degradation of emerging contaminants from water under natural sunlight: The effect of season, $\mathrm{pH}$, humic acids and nitrate and identification of photodegradation by-products. Chemosphere, 138, 675-681.

Kümmerer, K. (2009). The presence of pharmaceuticals in the environment due to human usepresent knowledge and future challenges. Journal of environmental management, 90(8), 2354-2366.

Lahti, M., \& Oikari, A. (2011). Pharmaceuticals in settleable particulate material in urban and nonurban waters. Chemosphere, 85(5), 826-831.

Lam, M. W., Young, C. J., Brain, R. A., Johnson, D. J., Hanson, M. A., Wilson, C. J., Richards, S. M., Solomon, K. R., \& Mabury, S. A. (2004). Aquatic persistence of eight pharmaceuticals in a microcosm study. Environmental Toxicology and Chemistry: An International Journal, 23(6), 1431-1440.

Leem (2020). Bilan économique, Edition 2020. Les entreprises du médicament.

Lin, A. Y. C., Lin, Y. C., \& Lee, W. N. (2014). Prevalence and sunlight photolysis of controlled and chemotherapeutic drugs in aqueous environments. Environmental pollution, 187, 170-181.

Liu, Q. T., \& Williams, H. E. (2007). Kinetics and degradation products for direct photolysis of $\beta$ blockers in water. Environmental science \& technology, 41(3), 803-810.

Löffler, D., Römbke, J., Meller, M., \& Ternes, T. A. (2005). Environmental fate of pharmaceuticals in water/sediment systems. Environmental science \& technology, 39(14), 5209-5218.

Loos, R., Gawlik, B. M., Locoro, G., Rimaviciute, E., Contini, S., \& Bidoglio, G. (2009). EU-wide survey of polar organic persistent pollutants in European river waters. Environmental pollution, 157(2), 561568.

Martínez-Hernández, V., Meffe, R., Herrera, S., Arranz, E., \& de Bustamante, I. (2014). Sorption/desorption of non-hydrophobic and ionisable pharmaceutical and personal care products from reclaimed water onto/from a natural sediment. Science of the total environment, 472, 273-281.

Maskaoui, K., \& Zhou, J. L. (2010). Colloids as a sink for certain pharmaceuticals in the aquatic environment. Environmental Science and Pollution Research, 17(4), 898-907.

Mompelat, S., Thomas, O., \& Le Bot, B. (2011). Contamination levels of human pharmaceutical compounds in French surface and drinking water. Journal of Environmental Monitoring, 13(10), 2929-2939.

Müller, M. E., Escher, B. I., Schwientek, M., Werneburg, M., Zarfl, C., \& Zwiener, C. (2018). Combining in vitro reporter gene bioassays with chemical analysis to assess changes in the water quality along the Ammer River, Southwestern Germany. Environmental sciences Europe, 30(1), 20.

Munoz, J. F. (2009). Résidus de médicaments dans les milieux aquatiques: besoins et outils pour la surveillance, évaluation des risques. Rapport Onema. 
Nunes, C. N., Dos Anjos, V. E., \& Quináia, S. P. (2019). Are there pharmaceutical compounds in sediments or in water? Determination of the distribution coefficient of benzodiazepine drugs in aquatic environment. Environmental Pollution, 251, 522-529.

Petrie, B., Barden, R., \& Kasprzyk-Hordern, B. (2015). A review on emerging contaminants in wastewaters and the environment: current knowledge, understudied areas and recommendations for future monitoring. Water research, 72, 3-27.

Ramil, M., El Aref, T., Fink, G., Scheurer, M., \& Ternes, T. A. (2010). Fate of beta blockers in aquaticsediment systems: sorption and biotransformation. Environmental science \& technology, 44(3), 962970.

Scheytt, T., Mersmann, P., Lindstädt, R., \& Heberer, T. (2005). Determination of sorption coefficients of pharmaceutically active substances carbamazepine, diclofenac, and ibuprofen, in sandy sediments. Chemosphere, 60(2), 245-253.

Schultz, M. M., Furlong, E. T., Kolpin, D. W., Werner, S. L., Schoenfuss, H. L., Barber, L. B., Blazer, V. S., Norris, D. O., \& Vajda, A. M. (2010). Antidepressant pharmaceuticals in two US effluent-impacted streams: occurrence and fate in water and sediment, and selective uptake in fish neural tissue. Environmental science \& technology, 44(6), 1918-1925.

Simonneau, A., Simonneau, J., Hatton, M. (2020) GranulomEtric pAssive Capture of dissOlved matter \& Sediment (GEACOS), Zenodo.

Soucémarianadin L., Verbèque, B. (2007). Notice explicative de la carte des sols de Orléans (1/50 000). Chambre d'agriculture du Loiret, Orléans.

Stein, K., Ramil, M., Fink, G., Sander, M., \& Ternes, T. A. (2008). Analysis and sorption of psychoactive drugs onto sediment. Environmental science \& technology, 42(17), 6415-6423.

Sumpter, J. P., Jobling, S., \& Tyler, C. R. (1996). Oestrogenic substances in the aquatic environment and their potential impact on animals, particularly fish. Seminar series-society for experimental biology, 57, 205-224.

Svahn, O., \& Björklund, E. (2015). Describing sorption of pharmaceuticals to lake and river sediments, and sewage sludge from UNESCO Biosphere Reserve Kristianstads Vattenrike by chromatographic asymmetry factors and recovery measurements. Journal of chromatography A, 1415, 73-82.

Tamtam, F., Mercier, F., Le Bot, B., Eurin, J., Dinh, Q. T., Clément, M., \& Chevreuil, M. (2008). Occurrence and fate of antibiotics in the Seine River in various hydrological conditions. Science of the Total Environment, 393(1), 84-95.

Tang, J., Wang, S., Fan, J., Long, S., Wang, L., Tang, C., Tam, N. F., \& Yang, Y. (2019). Predicting distribution coefficients for antibiotics in a river water-sediment using quantitative models based on their spatiotemporal variations. Science of the Total Environment, 655, 1301-1310.

Thiebault, T., Boussafir, M., Le Forestier, L., Le Milbeau, C., Monnin, L., \& Guégan, R. (2016). Competitive adsorption of a pool of pharmaceuticals onto a raw clay mineral. RSC advances, 6(69), 65257-65265.

Thiebault, T., Fougère, L., Destandau, E., Réty, M., \& Jacob, J. (2017a). Temporal dynamics of humanexcreted pollutants in wastewater treatment plant influents: Toward a better knowledge of mass load fluctuations. Science of the Total Environment, 596, 246-255.

Thiebault, T., Chassiot, L., Fougère, L., Destandau, E., Simonneau, A., Van Beek, P., Souhaut, M., \& Chapron, E. (2017b). Record of pharmaceutical products in river sediments: a powerful tool to assess the environmental impact of urban management?. Anthropocene, 18, 47-56. 
632

633

634

635

636

637

638

639

640

641

642

643

644

645

646

647

648

649

650

651

652

653

654

655

656

657

658

659

660

661

662

Thiebault, T. (2020). Raw and modified clays and clay minerals for the removal of pharmaceutical products from aqueous solutions: State of the art and future perspectives. Critical Reviews in Environmental Science and Technology, 50, 1451-1514.

Togola, A., Amalric, L., \& Bristeau, S. (2008). Les substances pharmaceutiques dans les eaux superficielles et souterraines du bassin Loire-Bretagne. Rapport final, BRGM/RP-55578-FR.

Vazquez-Roig, P., Segarra, R., Blasco, C., Andreu, V., \& Picó, Y. (2010). Determination of pharmaceuticals in soils and sediments by pressurized liquid extraction and liquid chromatography tandem mass spectrometry. Journal of Chromatography A, 1217(16), 2471-2483.

Vazquez-Roig, P., Andreu, V., Blasco, C., \& Picó, Y. (2012). Risk assessment on the presence of pharmaceuticals in sediments, soils and waters of the Pego-Oliva Marshlands (Valencia, eastern Spain). Science of the Total Environment, 440, 24-32.

Verlicchi, P., Galletti, A., Petrovic, M., \& Barceló, D. (2010). Hospital effluents as a source of emerging pollutants: an overview of micropollutants and sustainable treatment options. Journal of Hydrology, 389(3-4), 416-428.

Vystavna, Y., Le Coustumer, P., \& Huneau, F. (2013). Monitoring of trace metals and pharmaceuticals as anthropogenic and socio-economic indicators of urban and industrial impact on surface waters. Environmental monitoring and assessment, 185(4), 3581-3601.

Warner, W., Licha, T., \& Nödler, K. (2019). Qualitative and quantitative use of micropollutants as source and process indicators. A review. Science of the total environment, 686, 75-89.

Wilkinson, J. L., Hooda, P. S., Swinden, J., Barker, J., \& Barton, S. (2017). Spatial distribution of organic contaminants in three rivers of Southern England bound to suspended particulate material and dissolved in water. Science of the Total Environment, 593, 487-497.

Yamamoto, H., Nakamura, Y., Moriguchi, S., Nakamura, Y., Honda, Y., Tamura, I., Hirate, Y., Hayashi, A., \& Sekizawa, J. (2009). Persistence and partitioning of eight selected pharmaceuticals in the aquatic environment: laboratory photolysis, biodegradation, and sorption experiments. Water research, 43(2), 351-362.

Yu, J. T., Bouwer, E. J., \& Coelhan, M. (2006). Occurrence and biodegradability studies of selected pharmaceuticals and personal care products in sewage effluent. Agricultural water management, 86(1-2), 72-80.

Zhou, J., \& Broodbank, N. (2014). Sediment-water interactions of pharmaceutical residues in the river environment. Water research, 48, 61-70. 


\title{
SPATIAL DISTRIBUTION OF PHARMACEUTICALS WITHIN THE PARTICULATE PHASES OF A PERI-URBAN STREAM
}

\author{
L. Ledieu ${ }^{1}$, A. Simonneau ${ }^{1}$, T. Thiebault ${ }^{2}$, L. Fougere ${ }^{3}$, E. Destandau ${ }^{3}$, O. Cerdan ${ }^{4}$, F. Laggoun ${ }^{1}$
}

${ }^{1}$ Univ. Orléans, CNRS, BRGM, ISTO, UMR 7327, F-45071, Orléans, France (lauriane.ledieu@cnrs orleans.fr, anaelle.simonneau@univ-orleans.fr)

${ }^{2}$ EPHE, PSL University, UMR 7619 METIS (SU, CNRS, EPHE), 4 Place Jussieu, F-75005, Paris, France

${ }^{3}$ Univ Orleans, CNRS, ICOA, UMR 7311, 45067 Orleans, France

${ }^{4}$ BRGM, 3 avenue Claude Guillemin, 45060 Orléans, France

Table 1 : For each therapeutic molecule, abbreviation (Abb.), CAS-Number, formula, molecular weight (MW), charge state at $p H=7$ (Charge), pKa, solubility and $\log D$ are specified. ${ }^{a}$ : https://pubchem.ncbi.nlm.nih.gov; ${ }^{b}:$ www.drugbank.ca, ${ }^{c}$ : www.chemspider.com.

\begin{tabular}{|c|c|c|c|c|c|c|c|c|c|}
\hline $\begin{array}{c}\text { Therapeutic } \\
\text { group }\end{array}$ & Name & $A b b$. & $\begin{array}{c}\text { CAS- } \\
\text { Number }^{a}\end{array}$ & Formula $^{b}$ & $\begin{array}{c}M w \\
\left(g m o l^{-1}\right)^{b}\end{array}$ & Charge $e^{b}$ & $p K a^{b}$ & $\begin{array}{c}\text { Solubility } \\
\left(m g \cdot m L^{-1}\right)^{b}\end{array}$ & $\log D^{c}$ \\
\hline \multirow{2}{*}{ Analgesics } & Acetaminophen & $\mathrm{ACM}$ & $103-90-2$ & $\mathrm{C}_{8} \mathrm{H}_{9} \mathrm{NO}_{2}$ & 151.16 & 0 & 9.4 & 4.15 & 0.40 \\
\hline & Salicylic acid & SCA & $69-72-7$ & $\mathrm{C}_{7} \mathrm{H}_{6} \mathrm{O}_{3}$ & 138.12 & - & 3.5 & 11.3 & -0.77 \\
\hline Antibiotics & Trimethoprim & TRI & $738-70-5$ & $\mathrm{C}_{14} \mathrm{H}_{18} \mathrm{~N}_{4} \mathrm{O}_{3}$ & 290.32 & $0 /+$ & 7.2 & 0.62 & -1.15 \\
\hline $\begin{array}{l}\text { Non-steroidal } \\
\text { anti- } \\
\text { inflammatory } \\
\text { agents }\end{array}$ & Diclofenac & DIC & $15307-86-5$ & $\mathrm{C}_{14} \mathrm{H}_{11} \mathrm{Cl}_{2} \mathrm{NO}_{2}$ & 296.15 & - & 4.2 & 0.005 & 1.37 \\
\hline B-blockers & Atenolol & ATE & 29122-68-7 & $\mathrm{C}_{14} \mathrm{H}_{22} \mathrm{~N}_{2} \mathrm{O}_{3}$ & 266.34 & + & 9.6 & 0.43 & -1.85 \\
\hline \multirow{2}{*}{ Opioids } & Codeine & COD & $76-57-3$ & $\mathrm{C}_{18} \mathrm{H}_{21} \mathrm{NO}_{3}$ & 299.36 & + & 8.2 & 0.58 & 0.28 \\
\hline & Tramadol & TRA & $27203-92-5$ & $\mathrm{C}_{16} \mathrm{H}_{25} \mathrm{NO}_{2}$ & 263.38 & + & 9.4 & 0.75 & 0.52 \\
\hline Anticonvulsants & Carbamazepine & CBZ & $298-46-4$ & $\mathrm{C}_{15} \mathrm{H}_{12} \mathrm{~N}_{2} \mathrm{O}$ & 236.27 & 0 & 13.9 & 0.15 & 0.29 \\
\hline \multirow{2}{*}{ Psychotropics } & Diazepam & DIA & $439-14-5$ & $\mathrm{C}_{16} \mathrm{H}_{13} \mathrm{ClN}_{2} \mathrm{O}$ & 284.74 & 0 & 3.4 & 0.01 & 2.92 \\
\hline & Oxazepam & OXA & $604-75-1$ & $\mathrm{C}_{15} \mathrm{H}_{11} \mathrm{ClN}_{2} \mathrm{O}_{2}$ & 286.71 & 0 & 1.5 & 0.088 & 1.50 \\
\hline
\end{tabular}


Table 2: Solid-water partition coefficient (Kd), persistence and major degradation processes (BT: biotransformation; PY: photolysis) of the investigated analgesics, antibiotics, anti-inflammatory agents, 6-blockers, opioids and psychotropics.

\begin{tabular}{|c|c|c|c|c|}
\hline Therapeutic group & Molecule & $K d(L / k g)$ & Persistence & $\begin{array}{c}\text { Major degradation } \\
\text { processes }\end{array}$ \\
\hline \multirow[t]{2}{*}{ Analgesics } & ACM & $0.5-7.7^{p, v}$ & Low $^{1, w}$ & $\mathrm{BT}^{\mathrm{l}, \mathrm{w}}$ \\
\hline & SCA & $3.6-28.2^{a}$ & Low $^{c}$ & Both $^{c}$ \\
\hline Antibiotics & TRI & $18.84-104.6^{\mathrm{u}}$ & High $^{d, I}$ & Debated $^{c, l}$ \\
\hline $\begin{array}{l}\text { Non-steroidal } \\
\text { anti-inflammatory } \\
\text { agents }\end{array}$ & DIC & $0.2-107.1^{\mathrm{a}, \mathrm{f}, \mathrm{h}}$ & Low $^{b}$ & $P Y^{e, k}$ \\
\hline 8-blockers & ATE & $1.3-24.6^{\mathrm{f}, \mathrm{v}}$ & Moderate $^{\mathrm{d}, \mathrm{s}}$ & $B T^{n, s, v}$ \\
\hline \multirow[t]{2}{*}{ Opioids } & COD & $2.1-14.1^{t}$ & High $^{i}$ & $P Y^{m}$ \\
\hline & TRA & $23.7-63.1^{f, j}$ & Moderate $^{q}$ & $P Y^{q}$ \\
\hline \multirow[t]{3}{*}{ Psychotropics } & CBZ & $0.1-23.9^{\mathrm{j}, \mathrm{t}, \mathrm{v}}$ & High $^{d, I}$ & PY' \\
\hline & DIA & $2.3-12^{r}$ & $\mathrm{High}^{\circ}$ & $P Y^{e, g}$ \\
\hline & OXA & $2-38.5^{f, t}$ & Moderate $^{\circ}$ & $\mathrm{BT}^{\mathrm{g}}$ \\
\hline
\end{tabular}

References: ${ }^{a}$ Agunbiade and Moodley, $2015 ;{ }^{b}$ Ashton et al., $2004 ;{ }^{c}$ Baena-Nogueras et al., 2017; ${ }^{d}$ Bendz et al., 2005 ; ${ }^{e}$ Boreen et al., $2003 ;{ }^{f}$ Boulard et al., $2020 ;{ }^{9}$ Calisto and Esteves, 2009 ; ${ }^{h}$ Dobor et al., 2012 ; ${ }^{i}$ Fekadu et al., 2019 ; ${ }^{j}$ Koba et al. 2018 ; ${ }^{k}$ Koumaki et al., 2015 ; 'Lam et al., 2004; ${ }^{m}$ Lin et al., 2014 ; ${ }^{n}$ Liu et Williams, 2007; ${ }^{\circ}$ Löffler et al., 2005; ${ }^{p}$ Martínez-Hernández et al., 2014 ; ${ }^{q}$ Müller et al.,

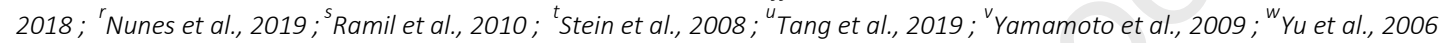




\section{SPATIAL DISTRIBUTION OF PHARMACEUTICALS WITHIN THE PARTICULATE PHASES OF A PERI-URBAN STREAM}

L. Ledieu ${ }^{1}$, A. Simonneau ${ }^{1}$, T. Thiebault ${ }^{2}$, L. Fougere ${ }^{3}$, E. Destandau ${ }^{3}$, O. Cerdan ${ }^{4}$, F. LAggoun ${ }^{1}$

${ }^{1}$ Univ. Orléans, CNRS, BRGM, ISTO, UMR 7327, F-45071, Orléans, France (lauriane.ledieu@cnrs orleans.fr, anaelle.simonneau@univ-orleans.fr)

${ }^{2}$ EPHE, PSL University, UMR 7619 METIS (SU, CNRS, EPHE), 4 Place Jussieu, F-75005, Paris, France

${ }^{3}$ Univ Orleans, CNRS, ICOA, UMR 7311, 45067 Orleans, France

${ }^{4}$ BRGM, 3 avenue Claude Guillemin, 45060 Orléans, France

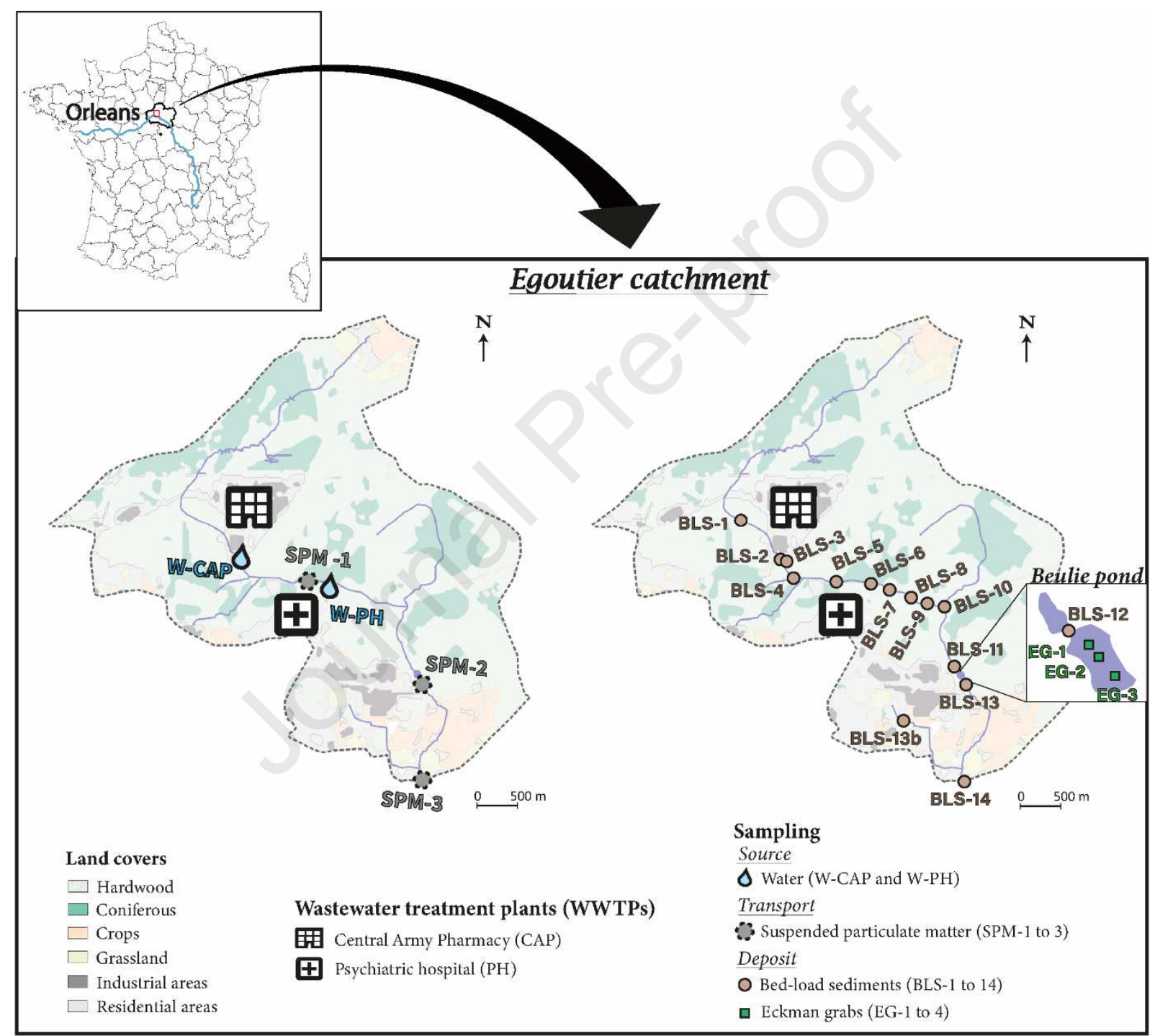

Figure 1 : Description of the upstream part of the Egoutier catchment area studied here with land covers (Inglada et al., 2017). Locations of the two sewage water effluents from the central army pharmacy (CAP) and the psychiatric hospital (PH) and of the samples collected in the dissolved phase (W), in suspended particulate matter (SPM), bed-load (BLS) and Beulie pond sediments (EG). 

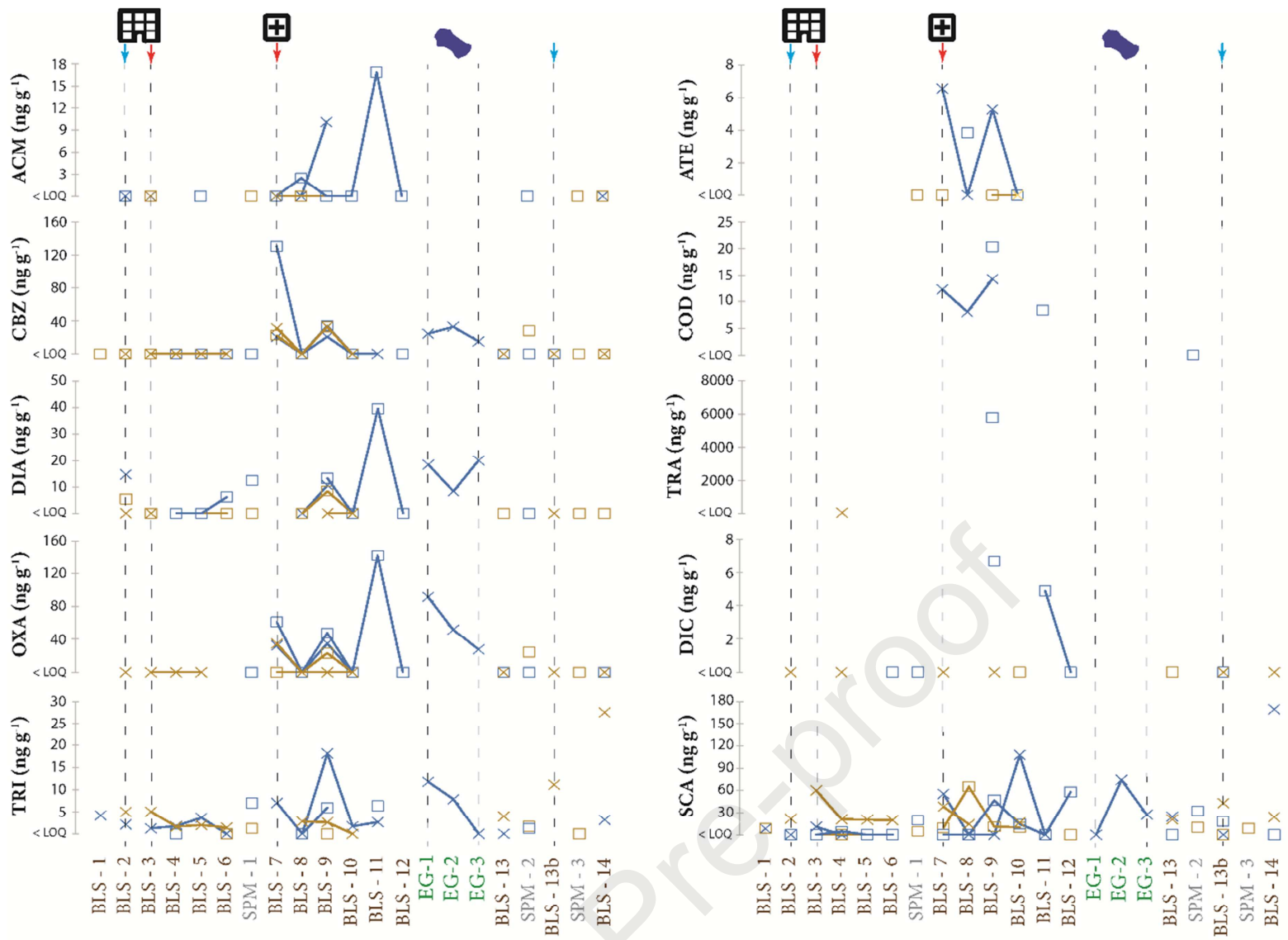

×2018 2019 - Spring - Summer $\rightarrow$ Stormwaters $\rightarrow$ Sewage waters 困Central Army Pharmacy $\mathbf{\boxplus}$ Psychiatric hospital

Beulie pond

Figure 2: Detection and concentrations of atenolol (ATE), codeine (COD), tramadol (TRA), acetaminophen (ACM), carbamazepine (CBZ), diazepam (DIA), oxazepam (OXA), trimethoprim (TRI), diclofenac (DIC) and salicylic acid (SCA) in bedload sediment samples (BLS 1 to 14, Fig. 1) along the watercourse during the different campaigns. Pharmaceutical mean contents in suspended particulate matter samples (SPM 1 to 3, Fig. 1) and Eckman grabs (EG 1 to 3, Fig. 1) according to sampling period. Dotted lines represent stormwater and sewage water effluents, as well as the Beulie pond location. 


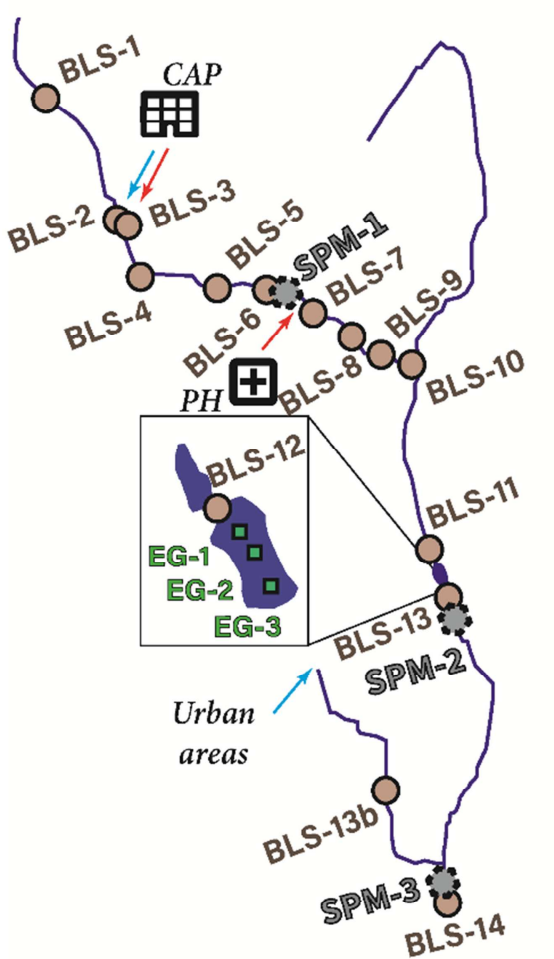

$\longrightarrow$ Storm waters $\longrightarrow$ Sewage waters

$\times 2018 \quad \square 2019 \quad$ - Spring - Summer

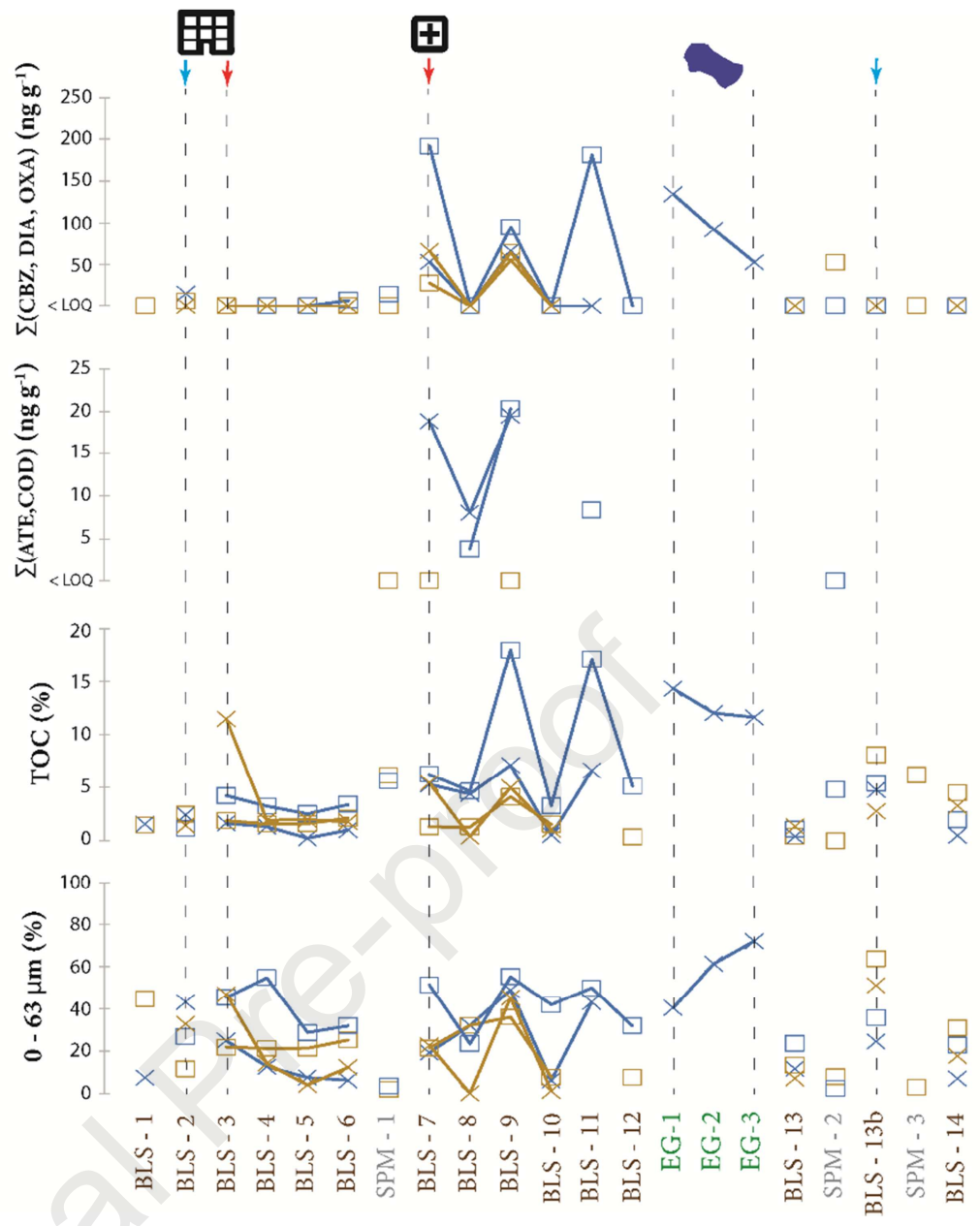

Figure 3: Spatial evolution of persistent neutral (carbamazepine (CBZ), diazepam (DIA) and oxazepam (OXA)) and cationic molecules (atenolol (ATE) and codeine (COD)) total concentrations $(\Sigma)$ compared to the spatial evolution of total organic carbon (TOC) and fine particles $(0-63 \mu \mathrm{m})$ percentages in suspended particulate matter (SPM 1 to 3, Fig. 1), bed-load (BLS 1 to 14, Fig. 1) and Beulie pond sediments (mean contents of EG 1 to 3, Fig. 1). 


\section{Highlights}

- Particulate phases well represent the PP diversity found in the dissolved fraction

- Organic matter content is the most important driver impacting the partition of PPs

- Most contaminated areas are discharging sites and sedimentary accumulation zones

- In the urban part of the catchment, transportation of particles is enhanced

- Seasonal variations depend on degradation, bearing phases and transfer distances 


\section{Declaration of interests}

$\bigotimes$ The authors declare that they have no known competing financial interests or personal relationships that could have appeared to influence the work reported in this paper.

$\square$ The authors declare the following financial interests/personal relationships which may be considered as potential competing interests: 